\title{
Evaluation of a cigarette holder for use in analytical smoking machines
}

\author{
M. HISSINK and R. BOSMAN \\ TNO, Division of Technology for Society, Apeldoom/Delfi, The Netherlands
}

\begin{abstract}
A cigarette holder that simulates the lips of a human smoker has been tested for use in measurements of yields of tar, nicotine, and carbon monoxide. In this study, we tested five different brands of cigarettes that ranged in tar yield from 1 to $15 \mathrm{mg}$ per cigarette. The dependence of the yields and ventilation rates on insertion depth and pressure exerted on the mouthpiece of the cigarette were investigated.
\end{abstract}

In many countries, cigarette brands sold to the public are ranked according to their yields of $\operatorname{tar}^{1}$, nicotine, and carbon monoxide. The yields are measured by testing the cigarettes on a smoking machine. Because the results have been found to vary according to the experimental procedure followed, much effort has been spent to standardize the measurement method. The essential details were laid down in publications by Pillsbury, Bright, $\mathrm{O}^{\prime}$ Connor, and Irish (1969) in the United States and by the Centre de Coopération pour les Recherches Scientifiques Rélatives au Tabac (1969) in Europe. Recently, the International Organization for Standardization (1986) and various national standardization organizations (e.g., Deutsches Institut für Normung, 1978; Nederlands Normalisatie Instituut, 1982) have issued standards based on these original publications.

Although the analytical methods differ slightly from one country to another, the estimates of yield thereby obtained are generally consistent. These standard measurement methods have been developed with full recognition that human smokers differ widely with respect to their smoking behavior and that an individual smoker will smoke differently from day to day or even from cigarette to cigarette. Several factors known to influence tar, nicotine, and carbon monoxide delivery of cigarettes are the smoker's mood swings; frequency, duration, and volume of the puffs; and the length of the butt. For the standard analytical procedures, the following values are generally chosen: one puff of $35 \mathrm{ml}$ lasts $2 \mathrm{sec}$, once per minute, and the butt length varies between 23 and $35 \mathrm{~mm}$, depending on the type of cigarette smoked. These values are somewhat different from the averages found in the population of smokers; however, this fact detracts very little from the significance of the brand rankings (Adams, 1966, 1976; Creighton \& Lewis, 1978; Rickert, Robinson, Young, Collishaw, \& Bray, 1983; Schulz \& Seehofer, 1978).

Recently there has been increased interest in the relevance of the data established by machine smoking according to standard procedures. To what extent can the

Reprint requests should be sent to the authors at: TNO, Division of Tochnology for Society, P.O. Box 342, 7300 AH Apeldoom, Apeldoorn, The Netherlands. measured yields provide a smoker with a realistic estimate of his/her individual intake? This issue was complicated even when nearly all cigarettes consumed were of one type; however, since the introduction of filter cigarettes and then of ventilated filters, the situation has grown more and more complex. The choice of cigarette brand depends to an increasing extent on the taste and smoking habits of the consumer, and there are increased possibilities for the smoker to influence the yield of the cigarette (Adams, 1978; Benowitz \& Jacob, 1984a; Gori, 1976; Gori \& Lynch, 1983; Russell, Sutton, Iyer, Feyerabend, \& Vesey, 1982; Schlotzhauer \& Chortyk, 1983). In this latter respect, blocking of the perforation holes by a smoker's fingers and the interaction between the cigarette and the smoker's lips have to be recognized as potentially important variables (Benowitz \& Jacob, 1984b; Kozlowski, Frecker, Khouw, \& Pope, 1980; Kozlowski, Rickert, Pope, Robinson, \& Frecker, 1982; Russell, Jarvis, Feyerabend, \& Saloojee, 1986).

The potential for interference of the smoker with the ventilation system of the cigarette has induced the individuals responsible for official testing of cigarettes to reconsider the testing methodology. Specifically, the holder for the cigarette used in the standard smoking procedure has received much attention, and a number of modifications have been proposed (Federal Trade Commission, 1985; International Organization for Standardization, 1983). Most of the modified holders have apparently been designed to block the ventilation of certain types of cigarettes; however, the Kamm holder, designed by Kamm and Fine ${ }^{2}$, mimics the normal interaction between the smoker's lips and the cigarette filter.

This paper describes experiments carried out in our smoking laboratory to evaluate the Kamm holder (1985) in standardized smoking routines. The effects of various parameters in the application of this holder were established for five brands of cigarettes. The results can be used to estimate effects on cigarette yields by the interaction of a smoker's lips with the cigarette filter. The influence of other factors, such as the difference between smoking parameters for humans and those for machines, are the subject of ongoing research. 


\section{DESCRIPTION OF THE KAMM HOLDER}

The body of the holder is machined from a cast acrylic rod, and the complete holder (see Figure 1) consists of four parts: the holder (housing), a collar for the connection of the holder to the filter holder, a silicone rubber tube mounted in the holder, and a stainless steel tube for the application of pressure to the holder.

The properties of the rubber tubing ${ }^{3}$ (thickness, $0.3 \mathrm{~mm}$; tensile modulus, $80 \mathrm{psi}$ at $100 \%$ elongation) are chosen to optimize the simulation of human lips. Since the tubing's internal diameter is matched to the external diameter of the cigarette, pressures applied to the chamber between the silicone rubber tube and the housing are transmitted to the cigarette without decrement. Insertion depth (the depth to which the cigarette is inserted into the holder) can vary from 4 to $12 \mathrm{~mm}$, the total depth of the holder.

To assemble the holder, the silicone rubber sleeve is inserted through the Plexiglas housing; a conical mold (see Figure 1) ensures correct and reproducible assembly. The two ends of the sleeve are folded back, and the position is secured by placing two O-rings in the grooves. Assembly is completed by inserting the holder with tubing into the collar. A filter holder (Gelman Instrument Co., Ann Arbor, MI 48106) is inserted into the other end of the collar.

\section{TEST}

\section{Determination of Tar, Nicotine, and Carbon Monoxide}

A Filtrona 302 (Filtrona Instruments \& Automation Ltd., Bletchley Milton Keynes, England) smoking machine was used for the regulation of the deliveries. A manifold was constructed to apply pressure or vacuum
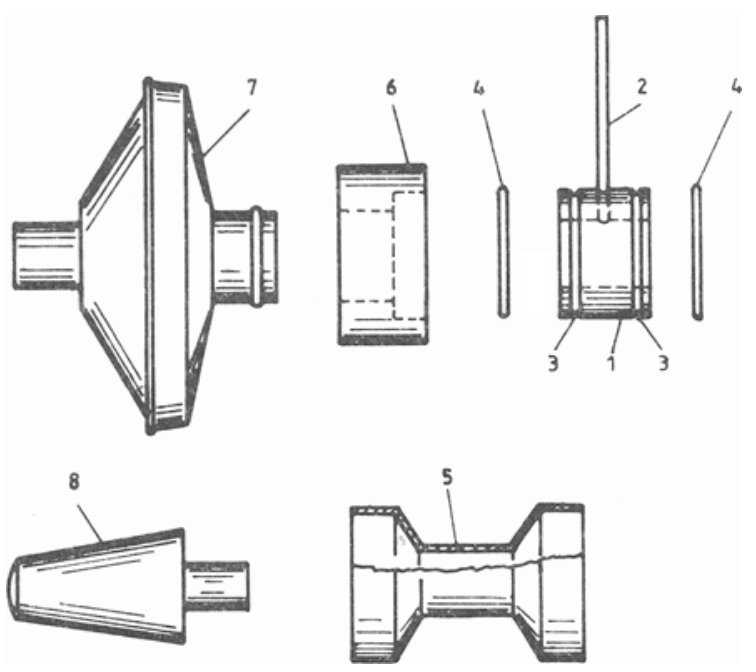

Figure 1. Enlarged view of Kamm holder with mold and Gelman filter: (1) housing, (2) stainless steel pressure tube, (3) annular grooves, (4) O-ring seals, (5) silicone rubber lining, (6) collar, (7) Gelman filter holder, and (8) conical mold.

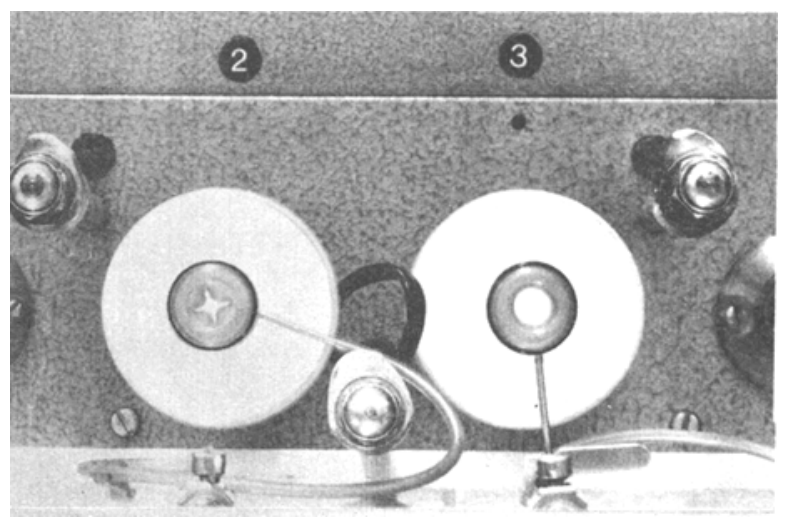

Figure 2. Kamm holder installed on Filtrona 302 smoking machine. Pressures: Left port, $85 \mathrm{~mm} \mathrm{Hg}$; right port, $0 \mathrm{~mm} \mathrm{Hg}$.

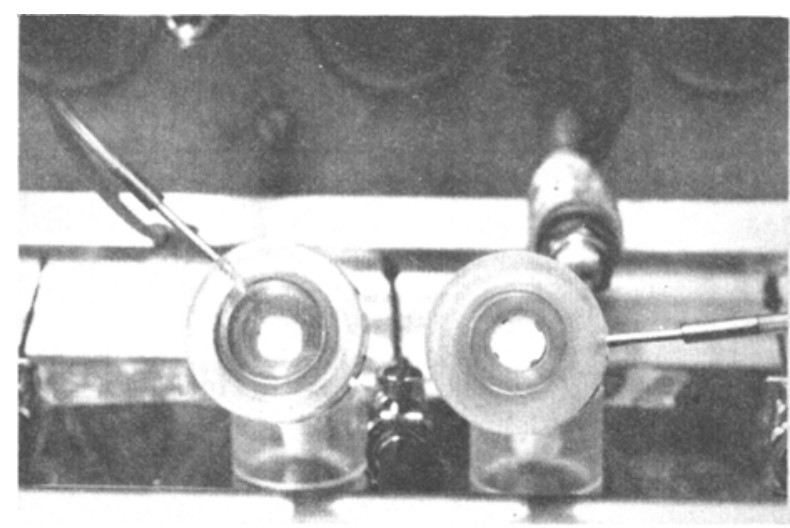

Figure 3. Kamm holder with cigarettes (9-mm insertion depth). Pressures: left port, 35 mm Hg; right port, 0 mm Hg.

to the Kamm holders, as shown in Figure 2. The holder mounted on the smoking port on the left shows the deformation of the rubber sleeve due to the applied pressure on the holder. Adapters were machined from acrylic rod to allow the mounting of the Gelman filter holders into the smoking ports. The pressure applied to the Kamm holders at the eight smoking ports was recorded on a manometer. The smoking routine followed the Dutch standard NEN 3382 (Nederlands Normalisatie Instituut, 1982; technically equivalent to ISO Draft Proposal 4387 by the International Organization for Standardization, 1986).

Figure 3 shows two Kamm holders with cigarettes inserted to a depth of $9 \mathrm{~mm}$. The application of a moderate pressure to the holder on the left causes a partial obstruction of the exit of the cigarette filter by the rubber sleeve.

Cigarettes were inserted to the chosen depth, and the required pressure was applied to the manifold. The insertion of the cigarettes is facilitated by the application of a low vacuum. During the test, we found that the use of the Kamm holder does not interfere with the normal operation of the smoking machine. In fact, we have found 


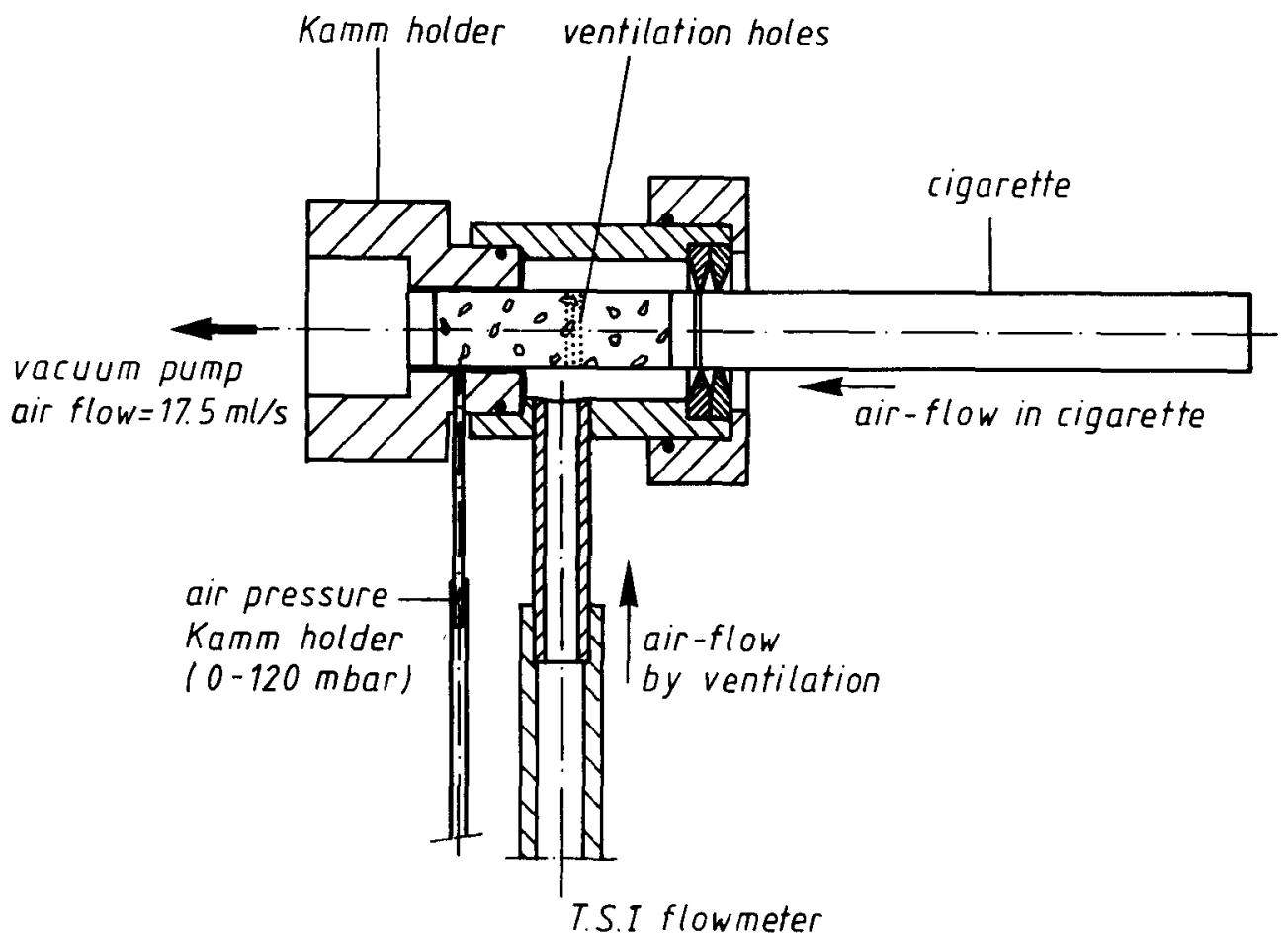

Figure 4. Equipment for ventilation rate measurement.

that the Kamm holder has some practical advantages over the normal holder with a labyrinth seal. For instance, when smoking is carried out with larger puff volumes and/or shorter puff durations than prescribed in the standard, the Kamm holder shows better resistance to leakage. The yields of tar, nicotine, and carbon monoxide were determined by smoking 10 cigarettes per filter. At each test condition, measurements were made six times; the averages are reported in the tables (in some cases, 20 replicate measurements were made).

The measurement of ventilation rates ${ }^{4}$ of cigarettes mounted in a Kamm holder was carried out using the equipment illustrated in Figure 4. A constant airflow of $17.5 \mathrm{ml} / \mathrm{sec}$ was applied to the butt end of the cigarette with the aid of a constant delivery pump. The airflow entering the cigarette via the ventilated filter was measured with a mass flowmeter (Thermo Systems Inc., Series 2230) and a linearizer (Thermo Systems Inc., Model 67). ${ }^{5}$
The same flowmeter was used for regular checks of the pump delivery. The results reported are averages calculated for 20 cigarettes. Measurements with different pressure/insertion adjustments were carried out on the same cigarette sample. This procedure was validated in a preliminary study.

In our experiments, five brands of cigarettes were used (see Table 1). Three brands (Marlboro, Peter Stuyvesant Extra Mild, and Peter Stuyvesant Ultra Mild) had a normal design for the ventilated filter; Barclay and St. Moritz Special were provided with a so-called channel-ventilated type of filter. Before the tests the cigarettes were conditioned for at least $48 \mathrm{~h}\left(22^{\circ} \mathrm{C}, 65 \%\right.$ relative humidity).

\section{Results and Discussion}

In Table 2, ventilation rates and deliveries of tar, nicotine, and carbon monoxide are given for the five brands of cigarettes. Insertion depths in the holder were adjusted

Table 1

Description of Cigarette Samples

\begin{tabular}{|c|c|c|c|c|c|}
\hline \multirow[b]{2}{*}{ Brand Name } & \multicolumn{2}{|c|}{$\begin{array}{l}\text { Imprint on } \\
\text { Package }\end{array}$} & \multicolumn{2}{|c|}{$\begin{array}{l}\text { Measured According } \\
\text { to NEN } 3382^{*} \\
\end{array}$} & \multirow[b]{2}{*}{ Filter Ventilation } \\
\hline & Tart & Nicotine $\dagger$ & Tart & Nicotine $\dagger$ & \\
\hline Marlboro & 16 & 1.1 & 14.5 & 0.87 & Low \\
\hline $\begin{array}{l}\text { Peter Stuyvesant } \\
\text { Extra Mild }\end{array}$ & 5 & 0.4 & 4.3 & 0.33 & Medium \\
\hline $\begin{array}{l}\text { Peter Stuyvesant } \\
\text { Ultra Mild }\end{array}$ & 1 & 0.1 & 1.5 & 0.12 & High \\
\hline Barclay KS & 1 & 0.2 & 0.8 & 0.07 & High; 4 Channels \\
\hline $\begin{array}{l}\text { St. Moritz } \\
\text { Special }\end{array}$ & 2 & 0.2 & 2.1 & 0.16 & High; 23 Channels \\
\hline
\end{tabular}

Special

*NEN 3382 is the Dutch standard established in 1982 by the Nederlands Normalisatie Instituut. †Measured in milligrams per cigarette. 
Table 2

Deliveries and Ventilation Rates for Five Brands of Cigarettes

\begin{tabular}{|c|c|c|c|c|c|c|c|c|c|c|}
\hline \multirow[b]{3}{*}{ Brand } & \multirow{3}{*}{$\begin{array}{l}\text { Insertion Depth } \\
\text { (in mm) }\end{array}$} & \multirow{3}{*}{$\begin{array}{c}\text { Pressure } \\
\text { (in } \mathrm{mm} \mathrm{Hg} \text { ) }\end{array}$} & \multicolumn{6}{|c|}{ Deliveries (in mg/cigarette) } & \multirow{2}{*}{\multicolumn{2}{|c|}{$\begin{array}{l}\text { Ventilation Rate* } \\
\text { (in Percent) }\end{array}$}} \\
\hline & & & \multicolumn{2}{|c|}{ Tar } & \multicolumn{2}{|c|}{ Nicotine } & \multicolumn{2}{|c|}{$\mathrm{CO}$} & & \\
\hline & & & Mean & $S D$ & Mean & $S D$ & Mean & $S D$ & Mean & $\overline{S D}$ \\
\hline \multirow[t]{5}{*}{$\overline{\text { Marlboro }}$} & 4 & 0 & 14.9 & 0.67 & 0.88 & 0.038 & 12.1 & 0.94 & 16.6 & 3.3 \\
\hline & 4 & 85 & 14.5 & 0.32 & 0.86 & 0.012 & 12.0 & 0.57 & 18.7 & 2.7 \\
\hline & 9 & 0 & 14.6 & 0.24 & 0.86 & 0.030 & 12.0 & 0.56 & 16.1 & 2.8 \\
\hline & 9 & 85 & 14.6 & 0.58 & 0.87 & 0.037 & 12.0 & 0.34 & 16.8 & 2.7 \\
\hline & $9 \dagger$ & $\mathrm{L}$ & 14.6 & 0.46 & 0.87 & 0.033 & 11.5 & 0.78 & 19.0 & 1.9 \\
\hline \multirow{5}{*}{$\begin{array}{l}\text { Peter Stuyvesant } \\
\text { Extra Mild }\end{array}$} & 4 & 0 & 4.8 & 0.22 & 0.34 & 0.017 & 4.6 & 0.30 & 49.4 & 3.2 \\
\hline & 4 & 85 & 4.9 & 0.13 & 0.34 & 0.009 & 5.0 & 0.21 & 49.1 & 3.1 \\
\hline & 9 & 0 & 4.9 & 0.20 & 0.35 & 0.013 & 5.0 & 0.37 & 47.9 & 4.0 \\
\hline & 9 & 85 & 5.0 & 0.18 & 0.35 & 0.008 & 4.8 & 0.18 & 47.8 & 4.0 \\
\hline & $9 \dagger$ & $\mathbf{L}$ & 4.3 & 0.39 & 0.33 & 0.028 & 4.0 & 0.35 & 49.6 & 3.7 \\
\hline \multirow{5}{*}{$\begin{array}{l}\text { Peter Stuyvesant } \\
\text { Ultra Mild }\end{array}$} & 4 & 0 & 1.7 & 0.16 & 0.13 & 0.016 & 1.9 & 0.06 & 68.4 & 2.5 \\
\hline & 4 & 85 & 1.7 & 0.13 & 0.13 & 0.006 & 1.9 & 0.05 & 67.6 & 2.3 \\
\hline & 9 & 0 & 1.6 & 0.16 & 0.12 & 0.011 & 1.8 & 0.22 & 67.7 & 2.4 \\
\hline & 9 & 85 & 1.5 & 0.31 & 0.13 & 0.010 & 1.6 & 0.18 & 67.7 & 2.4 \\
\hline & $9 \dagger$ & $\mathrm{L}$ & 1.5 & 0.15 & 0.12 & 0.007 & 1.6 & 0.20 & 69.6 & 3.1 \\
\hline \multirow[t]{5}{*}{ Barclay KS } & 4 & 0 & 1.0 & 0.16 & 0.09 & 0.013 & 0.9 & 0.17 & 81.2 & 4.0 \\
\hline & 4 & 85 & 2.5 & 0.42 & 0.42 & 0.048 & 2.8 & 0.58 & 65.2 & 10.3 \\
\hline & 9 & 0 & 1.1 & 0.25 & 0.08 & 0.013 & 1.0 & 0.15 & 81.0 & 3.0 \\
\hline & 9 & 85 & 1.2 & 0.26 & 0.11 & 0.032 & 1.9 & 0.61 & 78.3 & 2.8 \\
\hline & $9 \dagger$ & $\mathbf{L}$ & 0.9 & 0.19 & 0.08 & 0.022 & 0.7 & 0.25 & 81.2 & 3.4 \\
\hline \multirow{5}{*}{$\begin{array}{l}\text { St. Moritz } \\
\text { Special }\end{array}$} & 4 & 0 & 2.1 & 0.16 & 0.15 & 0.011 & 1.4 & 0.19 & 71.3 & 3.3 \\
\hline & 4 & 85 & 2.5 & 0.13 & 0.19 & 0.008 & 1.9 & 0.04 & 68.0 & 2.9 \\
\hline & 9 & 0 & 2.0 & 0.12 & 0.16 & 0.025 & 1.4 & 0.16 & 68.9 & 2.9 \\
\hline & 9 & 85 & 2.1 & 0.15 & 0.17 & 0.009 & 1.7 & 0.22 & 68.3 & 2.8 \\
\hline & $9 \dagger$ & $\mathrm{L}$ & 2.1 & 0.17 & 0.16 & 0.012 & 1.1 & 0.05 & 71.1 & 2.2 \\
\hline
\end{tabular}

Note-SD $=$ standard deviation (10 cigarettes smoked on each of 6 filters). $\mathrm{L}=$ labyrinth holder. $\quad$ *Ventilation rate measured on sample of 20 cigarettes. †NEN 3382 method.

at 4 and $9 \mathrm{~mm}$, and the applied pressure at 0 and $85 \mathrm{~mm} \mathrm{Hg}$. For comparison, we provide results obtained with the standard procedure (NEN 3382 with a cigarette holder having a labyrinth seal). For the three brands with normal ventilated filters, the Kamm holder produces virtually the same results as did the standard procedure, independent of the insertion depth and the applied pressure. For the two brands with ventilation channels, the yields of tar, nicotine, and carbon monoxide are significantly higher in a number of cases. Also, lower ventilation rates are found. The effects are most pronounced when low insertion depths are combined with high pressure, due to the partial obstruction or deformation of the ventilation channels (see Figure 3).

The reproducibility of the results obtained with the Kamm holder was investigated with regard to yields of tar and nicotine and ventilation rate for two brands of cigarettes (one with a low rate of ventilation and one with a high rate of channel ventilation). The results for the measurements of tar and nicotine are given in Table 3 . To obtain estimates of the reliability of the results, a 20 fold replication was used for each measurement. The results show that the means are concordant in all cases, and the reproducibility of measurements obtained with the Kamm holder tends to surpass that obtained with a labyrinth holder. In Table 4, the results are given for the measurements of the ventilation rates. Although the mean results show a high dependence on the conditions of use for the holder, the reproducibility is quite satisfactory, even when the measurements are repeated with the same cigarette under different conditions. This indicates that the cigarettes suffer negligible irreversible deformation in the Kamm holder.

A more detailed study of the influence of applied pressure and insertion depth was performed with the Barclay cigarette. A level of $8 \mathrm{~mm}$ was chosen for the insertion depth, because this depth is standard in the FTC method

Table 3

Reproducibility of Measured Yields

\begin{tabular}{|c|c|c|c|c|c|c|}
\hline \multirow[b]{3}{*}{ Brand } & \multirow{3}{*}{$\begin{array}{l}\text { Insertion } \\
\text { (in } \mathrm{mm} \text { ) }\end{array}$} & \multirow{3}{*}{$\begin{array}{c}\text { Pressure } \\
\text { (in } \mathrm{mm} \mathrm{Hg} \text { ) }\end{array}$} & \multicolumn{4}{|c|}{ Deliveries (in $\mathrm{mg} /$ cigarette) } \\
\hline & & & \multicolumn{2}{|c|}{ Tar } & \multicolumn{2}{|c|}{ Nicotine } \\
\hline & & & Mean & $S D$ & Mean & $S D$ \\
\hline \multirow[t]{3}{*}{ Barclay KS } & 9 & 0 & 0.93 & 0.12 & 0.07 & 0.013 \\
\hline & 9 & 35 & 1.04 & 0.16 & 0.07 & 0.016 \\
\hline & 9* & $\mathbf{L}$ & 0.99 & 0.28 & 0.08 & 0.017 \\
\hline \multirow[t]{3}{*}{ Marlboro } & 9 & 0 & 13.45 & 0.77 & 0.78 & 0.03 \\
\hline & 9 & 35 & 12.75 & 0.50 & 0.78 & 0.032 \\
\hline & $9 *$ & $\mathrm{~L}$ & 12.92 & 0.74 & 0.79 & 0.038 \\
\hline
\end{tabular}

Note-For each measurement, 10 cigarettes were smoked on each of 20 filters. $S D=$ standard deviation. $\mathrm{L}=$ labyrinth holder. $\quad{ }^{*} \mathrm{NEN}$ 3382 method. 
Table 4

Reproducibility of Measured Ventilation Rates

\begin{tabular}{|c|c|c|c|c|c|c|c|}
\hline \multirow[b]{2}{*}{ Brand } & \multirow{2}{*}{$\begin{array}{l}\text { Test } \\
\text { No. }\end{array}$} & \multirow{2}{*}{$\begin{array}{l}\text { Insertion } \\
\text { Depth } \\
\text { (in } \mathrm{mm} \text { ) }\end{array}$} & \multirow{2}{*}{$\begin{array}{c}\text { Pressure } \\
\text { (in } \mathrm{mm} \mathrm{Hg} \text { ) }\end{array}$} & \multicolumn{2}{|c|}{ 1st Measurement } & \multicolumn{2}{|c|}{ 2nd Measurement } \\
\hline & & & & Mean & $S D$ & Mean & $S D$ \\
\hline \multirow[t]{8}{*}{ Barclay KS } & 1 & 9 & 0 & 81.0 & 3.0 & & \\
\hline & 2 & 9 & 35 & 78.8 & 2.2 & 80.6 & 3.0 \\
\hline & 3 & 9 & 85 & 78.3 & 2.8 & 78.6 & 4.0 \\
\hline & 4 & 4 & 0 & 81.2 & 4.0 & 81.5 & 2.5 \\
\hline & 5 & 4 & 35 & 79.0 & 3.8 & 78.6 & 3.7 \\
\hline & 6 & 4 & 85 & 65.2 & 10.3 & 68.5 & 8.6 \\
\hline & $7^{*}$ & 9 & $\mathbf{L}$ & 81.2 & 3.4 & & \\
\hline & $8^{*}$ & 4 & $\mathbf{L}$ & 80.6 & 3.7 & & \\
\hline \multirow[t]{8}{*}{ Marlboro } & 1 & 9 & 0 & 18.7 & 2.7 & & \\
\hline & 2 & 9 & 35 & 18.2 & 2.4 & 18.4 & 2.8 \\
\hline & 3 & 9 & 85 & 16.1 & 2.8 & 18.6 & 2.7 \\
\hline & 4 & 4 & 0 & 16.6 & 3.3 & 17.2 & 2.6 \\
\hline & 5 & 4 & 35 & 16.2 & 2.2 & 17.2 & 2.7 \\
\hline & 6 & 4 & 85 & 16.8 & 2.7 & 17.0 & 2.7 \\
\hline & $7 *$ & 9 & $\mathbf{L}$ & 19.0 & 1.9 & & \\
\hline & $8^{*}$ & 4 & $\mathrm{~L}$ & 19.7 & 2.3 & & \\
\hline
\end{tabular}

Note-All reported results are means of 20 replications, in percent ventilation rate. $S D=$ standard deviation. $\mathrm{L}=$ labyrinth holder. $\quad$ *NEN 3382 method.

used in the United States. The results are in fair agreement with those reported in Table 2, taking into account that a different lot of Barclay cigarettes was used.

The influence of pressure and insertion depth on the yield of tar is illustrated in Figures 5 and 6. From these graphs, it is apparent that up to a pressure of $50 \mathrm{~mm} \mathrm{Hg}$, there is relatively little effect; the same is true for insertion depths of $8 \mathrm{~mm}$ and over. It is worthy of note that the average lip pressure in human smokers is about $35 \mathrm{~mm} \mathrm{Hg}$ (Kamm, 1985), whereas the average insertion depth is around 10-11 mm (U. Haevecker, personal com- munication, December 28, 1984). A significant increase of the yield is established only for combinations of low insertion depth and high pressure. The occurrence of these combinations is relatively rare in human smoking, even when one takes into account that pressures much higher and insertion depths much lower than average have been observed. Also, in addition to the effects examined in this study, other aspects of smoking behavior are important. Examples are the obstruction of the ventilation holes by the smoker with his/her fingers, increase in volume and frequency of puffs, and deeper inhalation. Therefore, fur-

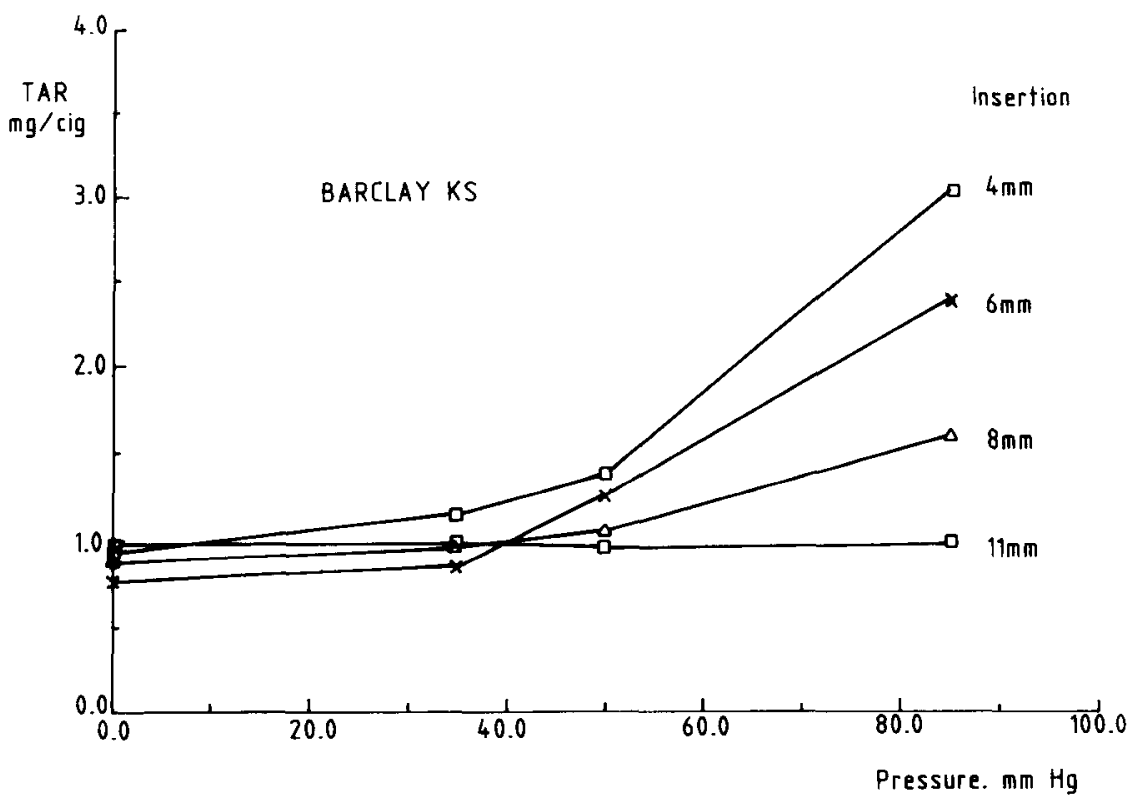

Figure 5. Influence of applied pressure on tar yield. 


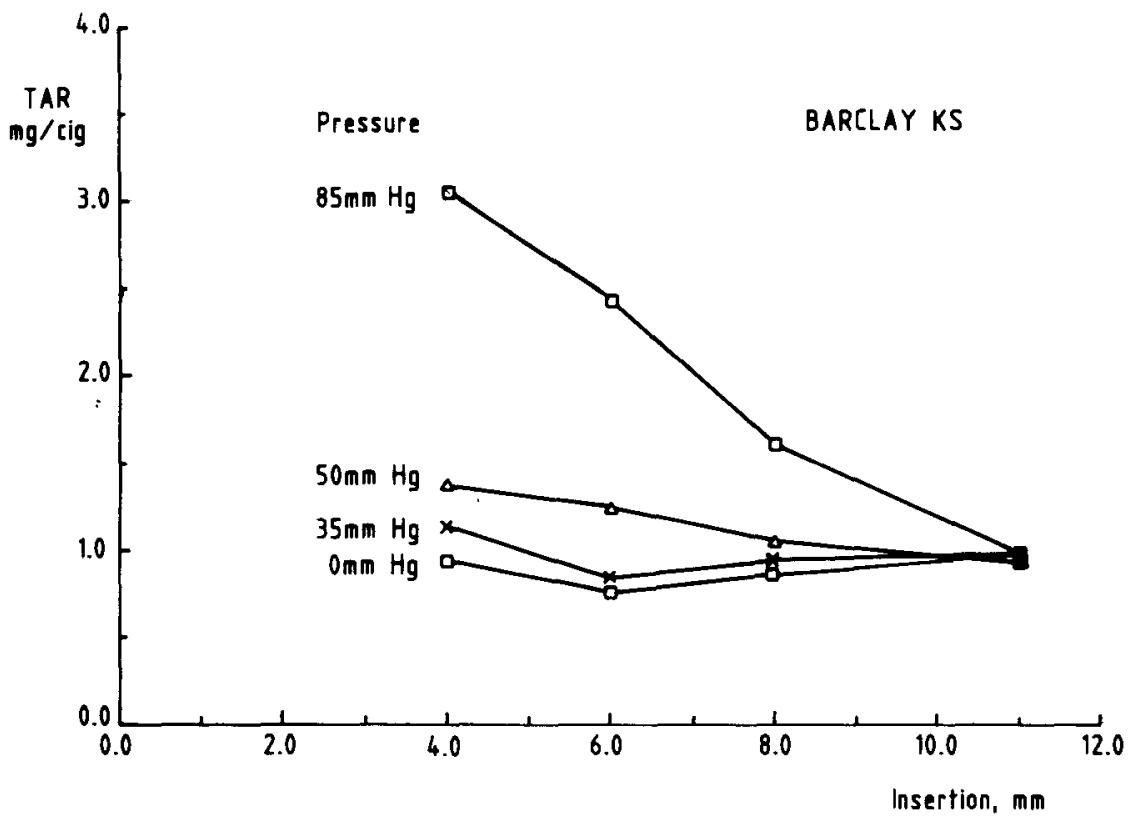

Figure 6. Influence of insertion depth on tar yield.

ther research needs to address the question of the significance of the results of machine smoking in evaluating the intake of smoke components during human smoking.

\section{REFERENCES}

Adams, P. I. (1966, November). Measurements on puffs taken by human smokers. Paper presented at the 20th Annual Tobacco Chemists' Research Conference, Winston Salem, NC.

ADAMs, P. I. (1976). Changes in personal smoking habits brought about by changes in cigarette smoke yields. Proceedings of the Sixth International Tobacco Science Congress (pp. 102-108). Paris: Coresta.

Adams, P. I. (1978). The influence of cigarette smoke yields on smoking habits. In R. E. Thornton (Ed.), Smoking behavior-Physiological \& psychological influences (pp. 349-360). Edinburgh: Churchill Livingstone.

BENowITZ, N. L., \& JACOB, P. (1984a). Daily intake of nicotine during cigarette smoking. Clinical Pharmacology \& Therapeutics, 35, 499-504.

BenowitZ, N. L., \& JACOB, P. (1984b). Nicotine and carbon monoxide intake from high- and low-yield cigarettes. Clinical Pharmacology \& Therapeutics, 36, 265-270.

Centre de Coopération pour les Recherches SCientifiques Rélarives AU TABAC. (1969). Coresta Standard method no. 10 (Sept. 1968)-Machine smoking of cigarettes, determination of crude and dry smoke condensate (Coresta information bulletin no. 1, pp. 2433). Paris: Author.

Creighton, D. E., \& Lewis, P. H. (1978). The effects of different cigarettes on human smoking patterns. In R. E. Thornton (Ed.), Smoking behaviour-Physiological \& psychological influences (pp. 289-300). Edinburgh: Churchill \& Livingstone.

DeUtsches INSTITUT Für NoRmung. (1978, April). (DIN 10 240).Maschinelles Abrauchen von Zigaretten und Bestimmung des Rauchkondensats (Deutsche Normen). Berlin: Beuth Verlag.

Federal Trade Commission. (1985, October 8). FTC proposes new procedures for cigarette testing methodology; seeks public comment on proposals. FTC News. Washington, DC: Author.

GORI, G. B. (1976). Low-risk cigarettes: A prescription. Science, 194, 1243-1246.

GORI, G. B., \& LYNCH, C. J. (1983). Smoker intake from cigarettes in the 1-mg Federal Trade Commission tar class. Regulatory Toxicology \& Pharmacology, 3, 110-120.

International Organization for Standardization. (1983, October). Resolution no. 40 adopted at the meeting of working group 3 of ISO/TC 126 (Sintra, Portugal).

International Organization fOr Standardization. (1986). Cigarettes-Machine smoking and determination of crude and dry condensate (ISO Draft Proposal 4387).

KAMM, R. D. (1985). Measurements of lip pressure exerted on a cigarette during normal smoking. Behavior Research Methods, Instruments, \& Computers, 17, 379-384.

Kozlowski, L. T., Frecker, R. F., Khouw, Y., \& PoPe, M. A. (1980). The misuse of "less hazardous" cigarettes and its detection. Hole blocking of ventilated filters. American Joumal of Public Health, 70, 1202-1203.

Kozlowski, L. T., Rickert, W. S., Pope, M. A., Robinson, J. C., \& FrECKER, R. C. (1982). Estimating the yield to smokers of tar, nicotine, and carbon monoxide from the "lowest yield" ventilated filter cigarettes. British Journal of Addiction to Alcohol \& Other Drugs, 77, 159-165.

NederLands Normalisatie INSTITUUt. (1982, March). NEN 3382Analyse van sigarettenrook. Delft: Author.

Pillsbury, H.C., Bright, C. C., O'Connor, K. J., \& Irish, F. W. (1969). Tar and nicotine in cigarette smoke. Journal of the Association of Analytical Chemists, 52, 458-462.

Rickert, W. S., Robinson, J. C., Young, J. C., Collishaw, N. E., \& BRAY, D. F. (1983). A comparison of the yields of tar, nicotine, and carbon monoxide of 36 brands of Canadian cigarettes tested under three conditions. Preventive Medicine, 12, 682-694.

Russell, M. A. H., Jarvis, M. J., Feyerabend, C., \& Saloojee, Y. (1986). Reduction of tar, nicotine and carbon monoxide intake in low tar smokers. Journal of Epidemiology \& Community Health, 40, 80-85.

Russell, M. A. H., Sutton, S. R., Iyer, R., Feyerabend, C., \& VeSEY, C. J. (1982). Long-term switching to low-tar low-nicotine cigarettes. British Journal of Addiction to Alcohol \& Other Drugs, 77, 145-158.

Schlotzhauer, W. S., \& ChorTyk, O. T. (1983). Effects of varied smoking machine parameters on deliveries of total particulate matter and selected smoke constituent from an ultra low-tar cigarette. Journal of Analytical Toxicology, 7, 92-95.

SCHULZ, W., \& SEEHOFER, F. (1978). Smoking behaviour in Germany- 
The analysis of butts (KIPA). In R. E. Thornton (Ed.), Smoking behaviour-Physiological \& psychological influences (pp. 259-276). Edinburgh: Churchill Livingstone.

\section{NOTES}

1. In this paper, we use the term tar to mean "particulate matter, water and nicotine free" (PMWNF), as it is customarily defined in various standards.

2. United States Patent 4,627,448, December 9, 1986-Tobacco smoke article holder and method therefor. The holder was designed by
Kamm and Fine, but it has become customary to use the name Kamm holder. In this paper, we follow this usage.

3. Manufactured by Bivona Surgical Instruments, Inc., Gary, IN.

4. Ventilation rate can be defined as the ratio of the air introduced in the filter section of the cigarette to the total puff volume. The measurement is usually carried out at a constant flow rate of $17.5 \mathrm{ml} / \mathrm{sec}$.

5. Thermo Systems, Inc., St. Paul, MN.

(Manuscript received December 10, 1985; revision accepted for publication September 26, 1986.)

\section{NOTICE}

\section{1th European Conference on Visual Perception August 31-September 3, 1988}

The 11th European Conference on Visual Perception will take place in Bristol, England from August 31 to September 3, 1988. The meeting covers psychophysical, physiological, and computational studies of the processes of visual perception relevant to human vision, including clinical and applied research of general scientific interest. A symposium on strategies in computer vision is planned to be included in the program, as are informal evening workshops.

Further information can be obtained from: Dr. Tom Troscianko, 11th ECVP, Brain and Perception Laboratory, The Medical School, University of Bristol, University Walk, Bristol BS8 1TD, England. The latest submission date for abstracts (for oral or poster presentation, and demonstration of equipment) is February 29, 1988. 